Revista Água Viva

\title{
CAMINHOS DO TRÁGICO NA PEÇA VAQUEIROS, DE OSWALD BARROSO
}

PATHWAYS OF THE TRAGIC IN THE VAQUEIROS, BY OSWALD BARROSO

André Luís Gomes ${ }^{1}$

Fabíula Martins Ramalho

RESUMO: A partir do conceito de Tragédia Moderna, de Raymond Williams e dos estudos sobre o trágico de Peter Zsondi e Terry Eagleton, o presente trabalho pretende analisar, do ponto de vista dialético-crítico, a peça Vaqueiros escrita em 1999 pelo dramaturgo e poeta cearense Oswald Barroso (1947). Permeada de elementos da cultura popular, Vaqueiros problematiza as relações de gênero numa tessitura teatral comprometida com a realidade e mostra uma sociedade, no sertão nordestino, marcada pelo arcaísmo e pela opressão social. Nosso objetivo identificar esses elementos e analisar como eles se relacionam com as questões abordadas, levando em consideração o texto dramatúrgico.

Palavras-chaves: Tragédia Moderna; Dramaturgia; Relações de gênero; Oswald Barroso.

ABSTRACT: From the concept of Modern Tragedy, Raymond Williams and the studies on the tragic of Peter Zsondi and Terry Eagleton, the present work intends to analyze, from a dialectical-critical point of view, the play Vaqueiros written in 1999 by the playwright and poet from Oswald, Oswald Barroso (1947). Pertaining to elements of popular culture, Vaqueiros problematizes the gender relations in a theatrical theater committed to reality and shows a society in the northeastern sertão, marked by archaism and social oppression. We aim to identify these elements and analyze how they relate to the issues addressed, taking into account the dramaturgical text.

Keywords: Modern Tragedy; Dramaturgy; Gender Relations; Oswald Barroso.

\footnotetext{
${ }^{1}$ Professor Associado do Departamento de Teoria Literária e Literatura (TEL) e credenciado no Programa de PósGraduação em Literatura (PósLIT/UnB) e no PROFARTES/UnB. Pós-Doutorado na Université de Rennes 2 (França). Doutor em Literatura pela FFLCH/USP. Coordenador do Grupo de Pesquisa Dramaturgia e Crítica Teatral (GDCT). E-mail: andrelg.unb@gmail.com

${ }^{2}$ Doutoranda do Programa de Pós-Graduação em Literatura da Universidade de Brasília (PósLIT/UnB), linha de pesquisa Literatura e outras Artes. Pesquisa de doutorado intitulada Entre folguedos, risos e engajamentos: as novas formas de representação da cultura popular no teatro de Oswald Barroso. E-mail: fabiulamr@ gmail.com
} 


\section{INTRODUÇÃO}

No contexto da história do panorama teatral brasileiro pode-se observar a contribuição do teatro nordestino para o desenvolvimento da dramaturgia nacional. O Nordeste é vasto. Cada tem estado tem suas especificidades. Por isso, a criação teatral ocorre a partir das influências diversas do contexto local. É o que acontece com o teatro cearense considerado "um tragicômico espetáculo de lutas, rezas e boas gargalhadas" (BARROSO, 2015, p. 365).

Atualmente, o teatro cearense tem ganhado notoriedade na cena regional e nacional. Todavia, antes de ocupar o espaço dos edifícios teatrais no século XIX, ele percorreu ruas, praças, terreiros, aliando a comédia de costumes ao drama social.

Com as mudanças de época, as temáticas sociais ganham força na dramaturgia cearense. A influência do Centro de Cultura Popular da União Nacional dos Estudante (CPC), de Augusto Boal, de José Celso Martinez e de espetáculos do Arena e do Opinião, abre caminhos para grupos comprometidos com o trabalho teatral e a formação de um teatro independente e de resistência.

Dessa maneira, observa-se a construção de um teatro que não trata apenas de problemáticas da sua região, mas de questões que afetam o país, mantendo "a preferência por temas e pela linguagem das tradições populares" (BARROSO, 2015, p. 369). Essa linguagem é usada para representar situações/pessoas em diferentes panoramas sociais, culturais e políticos, agregando conceitos e valores em consonância com os interesses de cada tempo.

Assim sendo, a linguagem teatral cearense tem encontrado novas formas textuais e estéticas para refletir as temáticas cotidianas e contemporâneas, como podemos observar no teatro do dramaturgo Oswald Barroso. Nascido em Fortaleza, ele sempre esteve comprometido com a pesquisa sobre a cultura popular, suas fontes representações, apropriações, usos e desdobramentos, atuando ativamente no cenário cultural cearense.

A sua criação teatral é permeada de matéria popular seguindo a vertente dos pioneiros da dramaturgia nordestina. No entanto, Oswald usa as fontes populares e tradicionais à sua maneira e desse modo coloca o seu teatro numa linha engajada que problematiza as questões sociais e suas conversões em diversos âmbitos: político, familiar, cultural, histórico:

[...] Toda a sua dramaturgia parece, assim, uma espécie de protesto, de ardente reivindicação a favor da liberdade e da justiça social, um libelo agônico contra o poder autoritário e sua prática de aniquilamento daqueles que o enfrentam. (JUNIOR, 2011, p. 14).

Neste contexto dramatúrgico que busca o enfrentamento dos conflitos vivenciados pela sociedade contemporânea, o presente artigo busca analisar como a peça Vaqueiros problematiza as 
relações de gênero e mostra "uma moral arcaica e opressiva" (BARROSO, 2002) ${ }^{3}$ a partir do conceito de tragédia moderna proposto por Raymond Williams, Peter Szondi e Terry Eagleton.

\section{Vaqueiros e os caminhos do trágico}

A tradição trágica influencia recorrentemente textos dramáticos modernos e contemporâneos. Muitas peças teatrais contemporâneas buscam por meio dessa tradição abordar temas importantes que envolvem o homem e a mulher na atualidade. A peça Vaqueiros está inserida nessa perspectiva ao tratar pelo viés trágico de questões que representam as mudanças de arquétipos sociais e culturais.

O que torna Vaqueiros uma tragédia permeada a ideia de trágico vai além das concepções formais e estruturantes. Trata-se da compreensão de que as temáticas contemporâneas relacionadas a pessoas comuns e marcadas pelo contexto histórico local podem ser compreendidas como tragédia, salientando a possibilidade de tragédia ou experiência trágica na modernidade ou contemporaneidade.

Escrita a partir da história de Dina, primeira mestra vaqueira cearense, e encenada em 2002 pela Companhia Boca Rica de Teatro $^{4}$, a peça tem quatro personagens pertencentes à mesma família: Vulcano (ferreiro e pai de Mira), Mira (vaqueira), Carneiro (comissário de polícia e esposo de Mira) e Lua (filha de Mira e Carneiro). Eles não são de classe social elevada e residem no interior nordestino exercendo suas atividades cotidianas.

O núcleo familiar da peça vive aprisionado pela memória de Raimundo, primeiro marido Mira, morto num suposto e misterioso acidente. Em uma noite, na ferraria de Vulcano, as marcas dessa memória nas relações familiares surgem de forma conflituosa e violenta, originando a tragédia anunciada logo no começo da peça, por Vulcano, num canto popular que prediz os acontecimentos futuros:

Guardando um silêncio profundo

Mais profundo que um poço de dor

A infanta a procura dos pais

Por fim junto ao quarto chegou.

E mesmo co'a porta fechada

Se ver o que lá se passou

Sentiu junto ao peito a pontada

Aviso de grane terror.

Gritou co'a voz engasgada

Prevendo o desfecho fatal:

Aqui só me cheira tragédia

Aqui me fede sangue real. (BARROSO, 2011, p.27).

\footnotetext{
${ }^{3}$ Citação retirada do artigo "Revelando os mecanismos de uma tragédia" que se encontra no Caderno Vida \& Arte do jornal $O$ Povo.

4 A companhia cearense, fundada em 1995, tem o objetivo de colocar em cena "um trabalho artístico e sociocultural" baseado "na pesquisa e na recriação das tradições cênicas populares". É formada por pesquisadores, artistas, professores, atores, atrizes, dançarinos, acrobatas, músicos.
} 
Assim como na tragédia clássica, desde o prenuncio inicial, configura-se a predestinação de Mira e Carneiro, ou seja, eles irão morrer. Mas as ações conflitantes, que levarão casal ao desfecho trágico, expõem ao leitor/espectador o problema das relações de gênero, numa sociedade patriarcal como a do sertão nordestino, e apresenta o arcaísmo e a opressão social que resiste as transformações de tempo, de comportamento e de vida. Portanto, ao observar a experiência trágica em Vaqueiros, compreende-se "mais a fundo o contorno e a conformação de uma cultura específica" (WILLIAMS, 2002, p. 69).

O título da peça se refere ao vaqueiro, portanto, aquele que na "cultura específica" do sertão é visto como cavaleiro e herói. Ele é "guerreiro encourado", "filho rude da caatinga", a sua figura faz parte da sociedade sertaneja desde a infância e marca o imaginário popular do sertão.

Considerado um personagem importante do denominado Ciclo do Couro, o vaqueiro é "um herói dissimulado". Personifica a liberdade, a coragem, a valentia, a força e o despojamento do homem sertanejo:

Caboclo quase índio, mais branco que negro, mais índio que branco, senhor do gado e das lonjuras, montado em seu cavalo, acompanhado de seu cachorro, vestido em seu gibão de couro, o vaqueiro é o cavaleiro do sertão. [...] Seu modo de ser nômade e despojado, seu apego à liberdade, sua imaginação rica e criativa, fixaram-se definitivamente na índole da gente do sertão. Dele descendem o cangaceiro, o beato e o cantador de viola. (BARROSO, 2015, p. 99-100).

O caráter libertário do vaqueiro ganha novas nuances na voz de Mira. Ao se assumir como mulher vaqueira, ela levanta bandeiras femininas, expõe um olhar diferente com relação trabalho do “cavaleiro do sertão”. Não quer viver sobre nenhum jugo.

No entanto, no texto dramatúrgico, Mira está presa ao vaqueiro Raimundo. Apesar de morto, ele parece sempre vivo devido as lembranças da vaqueira. Ele está frequentemente em sua memória. É o seu herói morto-vivo. Esta condição contrastante estabelece a identidade da vaqueira e individualiza a sua experiência, como diz Williams: "A vida que persiste tem como princípio formador a morte" (2002, p. 81).

A partir desse ciclo vida-morte, Mira ocupa um novo lugar como mulher, rompendo com os padrões de gênero e de comportamento na sociedade sertaneja. Pois, a imagem e a atividade do vaqueiro estão ligadas intrinsicamente ao universo masculino. Como viúva de Raimundo, Mira, assume o seu lugar, veste o gibão de couro, e se torna a líder dos vaqueiros da região. 
Esta sua nova posição social incomoda profundamente Carneiro não somente por ela se transformar em uma mulher vaqueira, mas principalmente pelo fato desta atividade mantê-la ainda mais ligada a memória do primeiro marido, as reminiscências de uma vida passada:

[...] o passado está, por assim dizer, presente na imagem como signo da sua ausência, mas trata-se de uma ausência que, não estando mais, é tida como tendo estado. Esse "tendo estado" é o que a memória se esforça por reencontrar. Ela reivindica a sua fidelidade a esse "tendo estado" (RICOEUR, $2003)^{5}$.

Com isso, Raimundo ergue-se como um fantasma na relação entre marido e mulher, o que possibilita "a cegueira trágica na qual os personagens estão imersos" (BARROSO, 2002). Cegueira provocada por experiências e por visões de mundo antagônicas que chegam a ser irremediáveis pela vivência em volta das sombras do passado e as marcas deixadas por uma sociedade hegemonicamente masculina. Em Vaqueiros, "as variações da experiência trágica devem ser interpretadas na sua relação com as convenções e as instituições em processo de transformação" (WILLIAMS, 2002, p. 70).

A partir dessa perspectiva, a experiência trágica da peça emerge da mudança no arquétipo social/familiar refletida no modo como Mira percebe o seu lugar no mundo. Junta-se a isso, a impossibilidade de comunicação entre ela e Carneiro devido a sua nova posição e a constante memória do vaqueiro morto: "O fato e a fonte da tragédia são agora, essencialmente, a inabilidade para comunicar-se" (WILLIAMS, 2011, p. 102).

Dessa dificuldade comunicativa, geradora de incompreensões e conflitos, a presença contextualizada de elementos da cultura popular, a linguagem do cordel e do bumba-meu-boi, possibilita uma forma de comunicação entre as personagens. Além de trazer certa leveza ao andamento dramático, apesar do fio trágico dos acontecimentos.

A história de cordel, contada para a Lua, simboliza os sentimentos que envolvem Mira e Carneiro. A narrativa é uma metáfora da vida do casal, pois, Mira representa uma princesa que vivia triste, por saudades do seu príncipe, e Carneiro dar voz a um menino pobre, filho de um pescador, que para casar-se com princesa aceitaria tornar-se igual ao príncipe amado por ela. Então, eles se casaram e tiveram uma filhinha. Porém, a união parece não trazer a felicidade esperada e Carneiro, como filho do pescador, diz:

[...] Acontece, que a princesa nunca tirou seu antigo príncipe da cabeça. Só falava nele, para tristeza do filho do pescador, que mesmo casado com a

\footnotetext{
${ }^{5}$ Citação retirada do texto "Memória, história, esquecimento", de Paul Ricoeur, que se encontra disponível em: <http://www.uc.pt/fluc/uidief/textos_ricoeur/memoria_historia>
} 
princesa nunca teve seu coração [...] Continuou encantado e seu consolo era sua filhinha, que ele também amava muito e parecia com a mãe (BARROSO, 2011, p. 44).

O bumba-meu-boi se relaciona com o clímax trágico da peça. Ao dialogar com a história da vaqueira e do seu marido, o espetáculo popular enraíza a tragédia "numa estrutura de sentimento precisa" (WILLIAMS, 2002, p. 36). Usando máscaras, Mira, Carneiro e Vulcano representam a brincadeira do boi. Aqui, Lua é expectadora. Ela sabe que é uma brincadeira, mas se assusta, fica com medo, pede que todos parem com o ato brincante. O caráter lúdico do bumba-meu-boi desvela os acontecimentos trágicos do futuro por meio de um jogo dramático rico em signos, símbolos, gestos.

As máscaras utilizadas pelas personagens durante a encenação do bumba-meu-boi, em que há momentos de luta e a ameaça de matar o boi, não são simplesmente adereços, mas simbolizam representações sociais. A máscara revela a trama trágica de cada personagem. Mesmo mascaradas, as personagens não deixam de representar as vozes dissonantes que lutarão até as últimas consequências para defender as suas posições no núcleo familiar e consequentemente na sociedade. Essas vozes devem ser interpretadas na sua relação com os padrões sociais já estabelecidos e com as transformações que ocorrem em diversas esferas da vida contemporânea.

No espetáculo popular dentro da peça encontra-se uma representação do pensar e do agir da sociedade sertaneja. Nele está presente o machismo que permeia todo o enredo de Vaqueiros como podemos observar na fala de Vulcano, como $\mathrm{Babau}^{6}$, ao se dirigir primeiramente a Carneiro, como Velho Careta $^{7}$, e depois a Mira: "Vulcano (Como Babau): Você não me mata porque eu sou também um vaqueiro. E você não é. (Para Mira). Nem você, sua atrevida, porque você pensa que é vaqueira como eu e não é (BARROSO, 2011, p. 50).

Assim, a partir de uma encenação de tradição popular, Vaqueiros mostra a sua metalinguagem teatral, possibilitando ao enredo dramático uma nova linguagem cênica, a criação de novos espaços interpretativos e formas diferentes de integração ou interação do leitor/expectador com o texto e a cena. Como diz Hermilo Borba Filho:

O bumba-meu-boi antecipou-se em séculos ao teatro anti-ilusionista de um Brecht, por exemplo, numa verdadeira teatralização do teatro: a ação não acontece mais neste ou naquele lugar imaginário, mas no próprio lugar da função. Fundem-se a realidade e a imaginação. Ao lado de cenas fingidamente reais, fazem-se referências ao próprio espetáculo [...] subvertem-se as

\footnotetext{
6 "O Babau é um cara mascarado, com a roupa de estopa e uma palhona de palmeira, ele escanchado naquela palhona, fazendo toda latomia, ali, com aquele pessoal. Rinchando que nem um animal, com uma cabeça de burro ou cavalo" (BARROSO, 2013, p. 236).

${ }^{7} \mathrm{O}$ velho careta é casado com a Velha. Eles formam o casal cômico na brincadeira do boi. São chefes da família dos Caretas, cada qual com sua profissão.
} 
unidades de tempo, lugar e ação, os objetos usados são quase sempre uma contrafação da realidade. (FILHO apud CARVALHEIRA, 2011) ${ }^{8}$.

A realidade em Vaqueiros reflete a subversão de uma mulher. Por isso, ao se assumir vaqueira, posto tipicamente masculino, Mira rompe com os padrões aceitáveis no sertão. Em algumas falas de Vulcano, tal ruptura mostra que certos tipos de comportamento não são esperados por uma mulher: "Não devia se usar, mulher sanfoneira. Faz procedimento que não é procedimento de mulher. Muito menos casada" (BARROSO, 2011, p. 28).

$\mathrm{O}$ fato de Mira não aceitar o lugar comum causa estranhamento e desordena a vida familiar. $\mathrm{Na}$ tentativa de manter a ordem, Vulcano coloca-se ao lado do genro contra o comportamento da filha. Eles buscam reagir a ameaça, provocada pela mulher vaqueira, a hegemonia masculina, denegrindo a imagem do vaqueiro morto:

Vulcano: Já vem, Mira, com a conversa daquele teu marido safado. Eu nunca quis teu casamento com ele. Carneiro: Essa besteira de gibão, de guarda-peito, perneira, arrastar boi no puxão. Conversa de vaqueiro, de sujeito sem instrução. (BARROSO, 2011, p.27-36).

Carneiro, ao desvalorizar a imagem do vaqueiro, busca o reconhecimento da mulher. Ele quer comandá-la. Apesar da insistência do sogro para colocar a esposa em "rédea curta", ele sabe que não é possível pôr "cabresto" em Mira:

Hoje a gente não pode mais tratar mulher com machismo. Você acabava era apanhando dela. (Silêncio) Vulcano você não pode compreender. Só conhece aqui esse trecho de cidade e os matos, essas fazendas velhas, acabadas, caindo aos pedaços, esses tempos passados (BARROSO, 2011, p. 36).

O contraste que "reflete com frequência uma batalha entre o passado e o presente" (EAGLETON, 2013, p. 206) problematiza o papel tradicional da mulher e do homem numa sociedade em mutação. Esta mudança exige reflexões, rupturas, novos caminhos para ser e estar no microcosmo social: "Novos tipos de relação e novos tipos de lei, que estabeleçam vínculos com o nosso sofrimento presente e o interpretem, são as condições da tragédia contemporânea" (WILLIAMS, 2002, p. 77).

O destino de Mira está predeterminado, mas a trajetória que ela percorre até chegar a sua sina possibilita a afirmação de sua identidade, a expressão de seus sentimentos, o levantamento de questões. No entanto, no seu percurso é possível observar o embate entre o velho e o novo, pois mesmo rompendo com os estereótipos, ela não deixa de reforçar a ideia de um homem idealizado por meio da figura do

\footnotetext{
${ }^{8}$ Citação utilizada por Luiz Maurício Carvalheira no livro "Por um teatro do povo e da terra: Hermilo Borba Filho e o Teatro do Estudante de Pernambuco, 2011, p. 86.
} 
seu marido morto: “[...] ela era o vaqueiro mais corajoso daqui. Não tinha medo de careta, nem de boi, nem de coronel” (BARROSO, 2011, p. 41).

A valorização da masculinidade do vaqueiro morto ocorre em detrimento ao homem urbano representado por Carneiro, estabelecendo um novo contraste: o sertão de um lado e a cidade do outro. Apesar de não gostar de Raimundo, Vulcano diz que a profissão de vaqueiro não é para quem nasceu na cidade. Essa declaração fere o ego do delegado de polícia, daquele que coloca na prisão os ameaçadores da sociedade. Então, para salientar a sua importância, Carneiro diz: "Prendi mais de mil bandidos e nunca sai nem na Patrulha do Rádio! Não sei porque esse povo da Capital se interessa tanto por vaqueiro. Vaqueiro é um miserável, um assalariado como outro qualquer. (BARROSO, 2011, p. 53).

Ao denegrir a imagem do vaqueiro, ele não busca só a sua valorização, mas também o reconhecimento da sua mulher. É um homem em ruínas, arraigado aos seus preconceitos, vivendo em seu arcaísmo temporal. Isso o torna um protagonista "desconjuntado, deslocado de seu tempo" (EAGLETON, 2013, p. 206) que já não encontra o seu espaço afetivo e social. Esta condição de Carneiro causa-lhe sofrimento e o coloca e uma posição irreconciliável.

Carneiro parece enxergar somente os seus sentimentos. Sente-se um marido traído por um fantasma. $\mathrm{O}$ fato de não ser o homem que permeia os pensamentos da esposa, inspirando-a em suas ações cotidianas, é uma ferida aberta que nunca cicatriza.

Ao entrar num ciclo vicioso, no qual não se projeta para além de si mesmo, Carneiro não deseja somente o amor incondicional da mulher, ele a quer como propriedade. Bêbado, portanto, sem o uso da razão, ele humilha Mira, faz uso da violência verbal, com xingamentos, tenta beijá-la a força. Pensa que tem direitos e poderes sobre a mulher pelo fato dele ser homem: "Você é minha mulher e tem que me servir" (BARROSO, 2011, p. 56).

O comportamento moralista e machista de Carneiro, a sua dificuldade de romper com as próprias ideias e abrir-se a uma nova conduta expõe justamente "o orgulho do homem confrontado com a natureza das coisas" (WILLIAMS, 2002, p. 77).

No caso, uma natureza em transformação que está culturalmente e historicamente condicionada a mudança de época, de crenças, estabelecendo a condição trágica que reflete uma luta entre o passado e o presente, entre a vida vivida e a vida idealizada, o arcaico e as mudanças sociais: "a verdadeira tensão entre o velho e o novo: entre crenças herdadas e incorporadas em instituições e reações, e contradições e possibilidades vivenciadas de forma nova e viva" (WILLIAMS, 2002, p. 79).

Nestes embates desenha-se a situação trágica, pois Mira e Carneiro começam um diálogo que fatalmente os levará ao um fim trágico. É interessante notar que todas as ações em Vaqueiros sempre ocorrem próximas a forja, ou seja, o lugar onde os metais são modelados pelo ferreiro. Carneiro e Vulcano querem modelar Mira. O pai de Mira passou a vida fabricando os ferros que o coronel usava para marcar os bois. Já o marido passou a vida prendendo bandidos. Para eles não há inovação, somente a repetição de comportamento, ações, valores, ideias. 
Assim, a presença continua do fogo parece simbolizar uma tentativa vã de iluminar a escuridão do relacionamento entre pai e filha, entre marido e mulher. $\mathrm{O}$ fogo pode ser associado a "um tipo de devaneio que comanda as crenças, as paixões, o ideal, a filosofia de toda uma vida" (BACHELARD, 1998, p. 5).

Então, diante desse fogo, os diálogos ficam mais tensos e Carneiro faz a primeira revelação trágica: o pai de Mira matou Raimundo o seu primeiro marido. Com a revelação da verdade e o fim do mistério sobre a morte do vaqueiro, Mira sente-se livre para expressar seus sentimentos, para reforçar suas escolhas e reafirmar sua posição, pois ela não é "uma mulherzinha obsedada pelo trabalho com o gado, mas a encarnação de uma guerreira" (BARROSO, 2002) .

A partir desse momento, Mira e Carneiro desenvolvem uma conversa marcada pelo conflito e pela solidão existencial de cada advinda das perdas emocionais, amorosas, familiares, sociais, que cada um carrega consigo:

Mira: Pois quer saber, eu amo Raimundo sim, e ainda, mais agora, sabendo disso. Trago ele dentro de mim. É ele que ainda hoje me faz ser alguém, me faz terem respeito por mim.

Carneiro: Você é uma mulher metida a vaqueiro, mas é uma mulher, o povo só lhe admira por isso, por achar esquisito, ficam falando, criticando.

Mira: Não, Carneiro, ficam achando bonito, ficam adorando. Você também, fica se babando. É por isso que você me quer, Carneiro, porque eu sou um vaqueiro, uma mulher valente, você se apaixonou por mim, porque eu sou uma vaqueira admirada como o Raimundo era. Você morre de inveja dele. Mas você queria ser assim como eu sou, como Raimundo era. Você está olhando para mim e pensa que eu sou eu, que

você está me vendo aqui, mas quem está aqui é o Raimundo, vivinho da Silva. Meu pai não conseguiu matá-lo, quanto mais você. (BARROSO,2011, p.57$58)$.

Ao expressar que ela e o marido morto são um só, Mira instiga ainda mais a raiva de Carneiro. Ele agora tem certeza que é um homem traído por um morto. Tomado pelo ódio, pois ele vê Mira como uma propriedade e não como sua esposa, Carneiro diz que vai marcar o que lhe pertence e mostrar quem é o verdadeiro vaqueiro.

Então, ele parte para cima de Mira com um ferro quente. A princípio, a vaqueira não acredita que o marido terá coragem de machucá-la e pede que ele pense na filha, mas Carneiro não consegue enxergar nada a não ser sua raiva e sua vontade de vingança, já que foi rejeitado por aquela que ele tanto desejou:

\footnotetext{
${ }^{9}$ Citação retirada do artigo "Revelando os mecanismos de uma tragédia" que se encontra no Caderno Vida \& Arte do jornal $O$ Povo.
} 
Mira: Você não tem coragem. Se lembre de Lua Carneiro: É por ela mesmo que vou fazer isso. Mira: Solta esse ferro, Carneiro! Solta esse ferro! Carneiro: Tá certo. Então você prefere uma faca. Tá certo, primeiro a gente tem que derrubar o boi, pra depois marcar, não é?

(BARROSO, 2011, p.59).

Com doses de crueldade, ele realiza "a ação irreparável": esfaqueia sua mulher. Depois pega um ferro em brasa e, com a vaqueira já morta, marca o rosto dela. Matou, como diz o pai de Mira, "pra ver se arrancava o chifre que lhe botou um morto" (BARROSO, 2011, p. 60).

Para vingar a morte da filha, Vulcano mata Carneiro. Ao final do seu ato, ele vê a neta que assistiu da porta da oficina a morte do pai. Lua acusa o avô pela morte dos pais: Lua: Você matou meu pai e minha mãe. Vulcano: Num foi eu. Foi ele que matou sua mãe. Lua: Foi você! (BARROSO, 2011, p.60-61)

Aqui cumpre-se o prenúncio inicial da tragédia. O leitor/espectador se depara com o destino cego dos personagens: a morte. No entanto, na peça, a morte ganha novos significados, pois a partir da experiência trágica pode-se ter um novo modo de perceber uma cultura, uma sociedade, abrindo caminhos de reflexão para as relações humanas e sociais. Como diz Raymond Williams: "Seja qual for o modo de morrer, a experiência não é apenas a dissolução física e de fim; ela diz respeito, também, a uma mudança na vida e na relação de outras pessoas" (WILLIAMS, 2002, p. 82).

Então, Lua junta o corpo do pai e da mãe, os abraça e adormece. Agora eles estão "enfim unidos e em paz" (BARROSO, 2011, p. 61). O único barulho que se ouve é de um trem. É a vida que segue a sua rota.

\section{CONSIDERAÇÕES FINAIS}

O trágico que se apresenta em Vaqueiros questiona "os significados mais profundos de uma cultura" (WILLIAMS, 2002, p. 81) por meio de pessoas comuns. Ao colocar no centro do texto ou da cena o conflito de um homem e uma mulher, a partir das mudanças sociais, a tragédia familiar reflete sobre a condição humana.

A experiência individualizada da mulher vaqueira dialoga com o coletivo para representar a problemática contemporânea das relações de gênero numa sociedade machista e conservadora.

Em Vaqueiros, o modo de perceber, ser e estar no mundo acontece por meio de pontos de vistas contrastantes que causam uma "desordem trágica". Então "a ação real incorpora o sentido particular, e tudo o que é geral nas obras a que chamamos tragédias é a dramatização de uma desordem específica e atroz, e sua resolução" (WILLIAMS, 2002, p. 78).

No caso de Vaqueiros a solução ocorre, como nas tragédias clássica, com a morte, pois “o trágico é um modus, um modo determinado de aniquilamento iminente ou consumado, é justamente o modo 
dialético" (SZONDI, 2004, p.84). Portanto, a morte na peça não representa o fim, mas uma síntese que personifica os dilemas de uma mudança de época, as paixões humanas, a memória, que nos consola e assombra, as idealizações e a realidade.

Assim os caminhos do trágico em Vaqueiros provocam o leitor/espectador a repensar e a reinterpretar os conflitos da contemporaneidade. Desse modo, a "tragédia passa a ser não um tipo de acontecimento único e permanente, mas uma série de experiências, convenções e instituições" (WILLIAMS, 2002, p. 70) em que não há vencidos e vencedores e, sim, sujeitos que desejam posicionarse no tempo/espaço num exercício de força simbólica em que a morte representa uma ferida aberta oriunda dos contrastes e das mudanças das relações de gênero na contemporaneidade.

\section{REFERÊNCIAS}

BACHELARD, Gaston. A água e os sonhos: ensaio sobre a imaginação da matéria. Tradução de Antônio de P. Danesi. São Paulo: Martins Fontes, 1998.

BARROSO, Oswald. Entre ritos, risos e batalhas. Fortaleza: Secult/CE, 2011.

Teatro de moleques e santos guerreiros. In: Ceará Mestiço. Fortaleza: Armazém da Cultura, 2015.

Babau. In: Teatro como encantamento: bois e reisados de caretas. Fortaleza:

Armazém da Cultura, 2013.

. Revelando os mecanismos de uma tragédia. Fortaleza, mar. 2012. Caderno Vida \& Arte do jornal O Povo. 2015 .

O cavaleiro andante do Sertão. In: Ceará Mestiço. Fortaleza: Armazém da Cultura,

CARVALHEIRA, Luiz Maurício Britto. Por um teatro do povo e da terra: Hermilo Borba Filho e o Teatro do Estudante de Pernambuco. Recife: CEPE, 2011.

EAGLETON, Terry. Doce violência: a ideia de trágico. Tradução de Alzira Allegro. São Paulo: Editora Unesp, 2013.

JÚNIOR, Carlos Newton. Oswald Barroso e o Teatro Nordestino. In: Entre ritos, risos e batalhas. Fortaleza: Secult/CE, 2011.

RICOEUR, Paul. Memória, história, esquecimento. Disponível em:

<http://www.uc.pt/fluc/uidief/textos_ricoeur/memoria_historia>. Acesso em: 20 jun. 2017.

SZONDI, Peter. Ensaio sobre o trágico. Tradução de Pedro Süssekind. Rio de Janeiro: Jorge Zahar Editora, 2004. 
WILLIAMS, Raymond. Tragédia Moderna. Tradução de Betina Bischof. São Paulo: Cosac \& Naify, 2002.

Política do modernismo: contra os novos conformistas. Tradução de André Glaser. São Paulo: Editora Unesp, 2011.

Recebido em: 15 jun. 2018

Aceito em: 01 jul. 2018 